\title{
Pengembangan Sayuran Lokal dengan Vertikultur pada Pekarangan Keluarga (Family Farming)
}

\author{
Catur Wasonowati ${ }^{{ }^{*}}$ \\ ${ }^{1}$ Prodi Agroteknologi Fakultas Pertanian Universitas Trunojoyo Madura \\ Jl. Raya Telang 02 Kamal Bangkalan Madura 69162 Jawa Timur \\ *E-mail : caturwasonowati@gmail.com \\ DOI: https://doi.org/10.21107/pangabdhi.v7i1.8809 \\ Naskah diterima 29 September 2020, Revisi 15 Maret 2021, Terbit 29 April 2021
}

\begin{abstract}
Indonesia is a country that has abundant biodiversity including local vegetable crops that have long been consumed by the Indonesian people, so it was necessary to increase productivity, production, and quality with various innovations that are cheap and easy to apply. Verticulture is an agricultural cultivation system that was carried out vertically or stratified and a technique of cultivating vegetables on limited land which was arranged in layers with a particular container model by applying advanced technology packages and high economic value commodities. This verticulture can be applied in the Family Farming. This family farming program will affect food security and fulfillment of nutrition for each family. Abdimas activities was carried out in Socah Village, Socah District, Bangkalan Regency, consisting of the introduction and training of the local vegetable crop verticulture method as well as assistance in the use of family farming and narrow land for housewives or the community so that later it can improve the ability of housewives or the community economically and socially in meeting the nutritional needs of families and communities.
\end{abstract}

Key Words : nutrition, family farming, local vegetables, verticulture.

\section{PENDAHULUAN}

Pangan merupakan kebutuhan mendasar bagi manusia, sehingga harus terpenuhi baik dalam jumlah, mutu, bergizi seimbang, aman dan terjangkau bagi setiap orang. Program pekarangan keluarga (Family Farming) ini, dapat mendukung ketahanan pangan pada setiap keluarga yang dipastikan akan lebih mantap, karena semua anggota keluarga nantinya akan berkontribusi dalam menjaga ketahanan pangannya. Konsep pertanian keluarga yang memanfaatkan pekarangan rumah atau lahan sempit ini untuk menjaga ketahanan pangan sebagai imbas pandemi Covid-19. Lahan perkarangan memiliki potensi dalam penyediaan bahan pangan bagi keluarga, sehingga pengeluaran rumah tangga untuk membeli bahan pangan dapat dikurangi dan meningkatkan pendapatan rumah tangga jika produksi bahan pangan berlimpah terutama sayur-sayuran yang higienis dan sehat bagi keluarga (Hidayati et al., 2018).

Indonesia termasuk negara yang mempunyai keanekaragaman hayati yang melimpah termasuk tanaman sayuran lokal. Sayuran lokal sudah lama dikonsumsi oleh masyarakat Indonesia. Jenis sayuran lokal ini sering disebut sayuran indigenous. Sayuran lokal semakin diminati oleh masyarakat sehingga diperlukan peningkatan produktivitas, produksi, dan kualitasnya dengan berbagai inovasi yang murah dan mudah diaplikasikan. Tren ini menunjukkan bahwa potensi pengembangan produk-produk sayuran lokal ini mempunyai prospek yang baik dan menjanjikan (Rukmana dan Yudirachman, 2016).

Budidaya sayuran dengan metode vertikultur sangat bermanfaat dan hemat sehingga cocok untuk daerah yang berpenduduk padat. Vertikultur merupakan sistem budidaya pertanian yang dilakukan secara vertikal atau bertingkat dan merupakan suatu teknik budidaya tanaman sayuran di lahan terbatas yang di atur secara bersusun menggunakan bangunan atau tempat khusus atau model wadah tertentu dengan menerapkan paket teknologi maju, dan komoditas bernilai ekonomi tinggi.

Budidaya tanaman sayuran secara vertikultur ini sangat penting diterapkan pada masyarakat Desa Socah dengan sasaran ibu-ibu rumah tangga dengan tujuan agar rumah tangga dapat meningkat pendapatannya, pemenuhan gizi keluarga dan agar tersedia pangan lestari, sehingga perlu dilakukan kegiatan abdimas ini. 
Kelompok sasaran yang dituju adalah ibu-ibu rumah tangga atau masyarakat di Desa Socah Kecamatan Socah Kabupaten Bangkalan. Pada lokasi tersebut pemanfaatan pekarangan keluarga masih belum optimal dan lahan kosong juga semakin berkurang karena digunakan untuk perumahan. Hal ini disebabkan karena kurangnya kesadaran dan pengetahuan ibu-ibu rumah tangga atau masyarakat dalam memanfaatkan lahan pekarangan dan lahan sempit yang ada di sekitar rumah. Sehingga pemenuhan kebutuhan sayuran sehari-hari tergantung dari ketersediaan sayuran di pasar yang kondisinya kadang sudah tidak segar lagi, berbeda jika memetik langsung dari pekarangan sendiri. Dari permasalahan tersebut, perlu adanya solusi untuk memanfaatkan lahan pekarangan dan lahan sempit untuk membantu penyediaan sayuran lokal sebagai sumber gizi keluarga melalui pemanfaatan pekarangan dan lahan sempit dengan metode vertikultur.

\section{METODE}

Metode dari kegiatan abdimas ini dilakukan dengan cara memberi pelatihan dan pendampingan pada budidaya tanaman sayuran lokal secara vertikultur. Rangkaian kegiatan pengabdian kepada masyarakat (abdimas) ini dilakukan melalui beberapa tahap, yaitu antara lain:

1. Survey lokasi, kegiatan ini dilaksanakan untuk melihat kondisi lingkungan di lokasi sasaran sekaligus untuk meminta ijin kerjasama kepada pihak tertentu terkait pelaksanaan kegiatan pengabdian kepada masyarakat.

2. Sosialisasi program dengan menyampaikan maksud dan tujuan kegiatan serta altenatif solusi permasalahan yang akan dilakukan dalam kegiatan pengabdian kepada masyarakat.

3. Pelaksanaan pelatihan dan pendampingan kelompok sasaran ibu-ibu rumah tangga atau masyarakat dengan mengikutsertakan mahasiswa KKN UTM 2020. Pada tahapan ini tim akan memberikan pelatihan teknik budidaya tanaman sayuran lokal dengan metode vertikultur dan layanan pendampingan kelompok sasaran ibu rumah tangga atau masyarakat selama periode pengabdian kepada masyarakat berlangsung jika kelompok sasaran membutuhkan.

4. Evaluasi dan monitoring, pada tahapan ini tim akan melakukan evaluasi dan monitoring terkait pelaksanaan dan dampak yang ditimbulkan dari kegiatan pengabdian kepada masyarakat.

Adapun bahan yang digunakan dalam kegiatan abdimas ini adalah benih sayuran, media tanam, media semai (rockwoll), kompos, pupuk NPK. Sedangkan alat yang digunakan dalam kegiatan abdimas adalah rak besi, pot, paralon, pot tempel, pot dari karung, polibag, gembor, handspayer. Pelaksanaan dari kegiatan abdimas dengan pengembangan vertikultur sayuran lokal selama 4 bulan mulai Juli sampai dengan November 2020 di Desa Socah Kecamatan Socah Kabupaten Bangkalan.

\section{HASIL DAN PEMBAHASAN \\ Kondisi Umum Lokasi}

Secara geografis Desa Socah berada di wilayah Kecamatan Socah yang merupakan salah satu kecamatan dari 18 kecamatan di Kabupaten Bangkalan. Kecamatan Socah terdiri dari 11 desa yang salah satunya adalah Desa Socah. Luas Desa Socah $\pm 1.15 \mathrm{~km}^{2}$. Desa Socah memiliki 7 kampung/dusun, $7 \mathrm{RW}$ dan 25 RT. Jumalh penduduk sekitar \pm 7.323 jiwa. Jarak Desa Socah ke Kabupaten Bangkalan $\pm 8 \mathrm{~km}$ dapat ditempuh dalam waktu 30 menit dengan menggunakan kendaraan umum. Posisi desa ini di sebelah selatan dan utara, berbatasan dengan Desa Telang dan Keleyan, sedangkan di bagian timur dan barat berbatasan dengan Desa Buluh dan Desa Petaonan. Mata pencaharian masyarakat bervariasi.

\section{Pelatihan Vertikultur Tanaman Sayuran Lokal}

Tanaman sayuran lokal yang dibudidayakan dengan teknik vertikultur merupakan usaha budidaya tanaman dengan cara vertikal atau bertingkat baik dilakukan di dalam ruangan maupun di luar ruangan. Sistem budidaya pertanian secara vertikal atau bertingkat ini merupakan konsep penghijauan yang sesuai untuk daerah lahan terbatas (sempit) dan kurang subur. Pada luasan lahan 1 meter bisa digunakan untuk menanam 5 tanaman, dengan sistem vertikal bisa untuk sekitar 20 tanaman (Lukman, 2010).

Teknologi vertikultur dari model, ukuran, bahan, dan wadah vertikultur sangat bervariasi dan bisa disesuaikan dengan kondisi sekitar dan keinginan dari pembuat. Pada umumnya bentuk dari vertikultur adalah berbentuk persegi panjang, segi tiga, atau dibentuk mirip anak tangga dengan sejumlah rak. Bahan yang digunakan untuk vertikultur dapat berupa pipa paralon, bambu 
kaleng bekas, botol dan gelas plastik air mineral, kantong tempel yang berasal dari bahan lembaran karung beras dan alat-alat rumah tangga yang sudah tidak dipakai lagi seperti ember, kaleng, jirigen, botol minyak goreng sterofoam dan lainlain. Salah satu filosofi dari vertikultur adalah memanfaatkan benda-benda bekas di sekitar tempat tinggal (Nurlaili dan Gribaldi, 2015).

Persyaratan dari teknik vertikultur adalah kuat dan mudah dipindah-pindahkan. Tanaman yang digunakan untuk budidaya secara vertikultur sebaiknya disesuaikan dengan kebutuhan dan memiliki nilai ekonomis tinggi berumur pendek. Tanaman sayuran lokal yang dibudidayakan dengan teknik vertikultur antara lain selada, kangkung, bayam, sawi, kacang panjang dan lain lain.

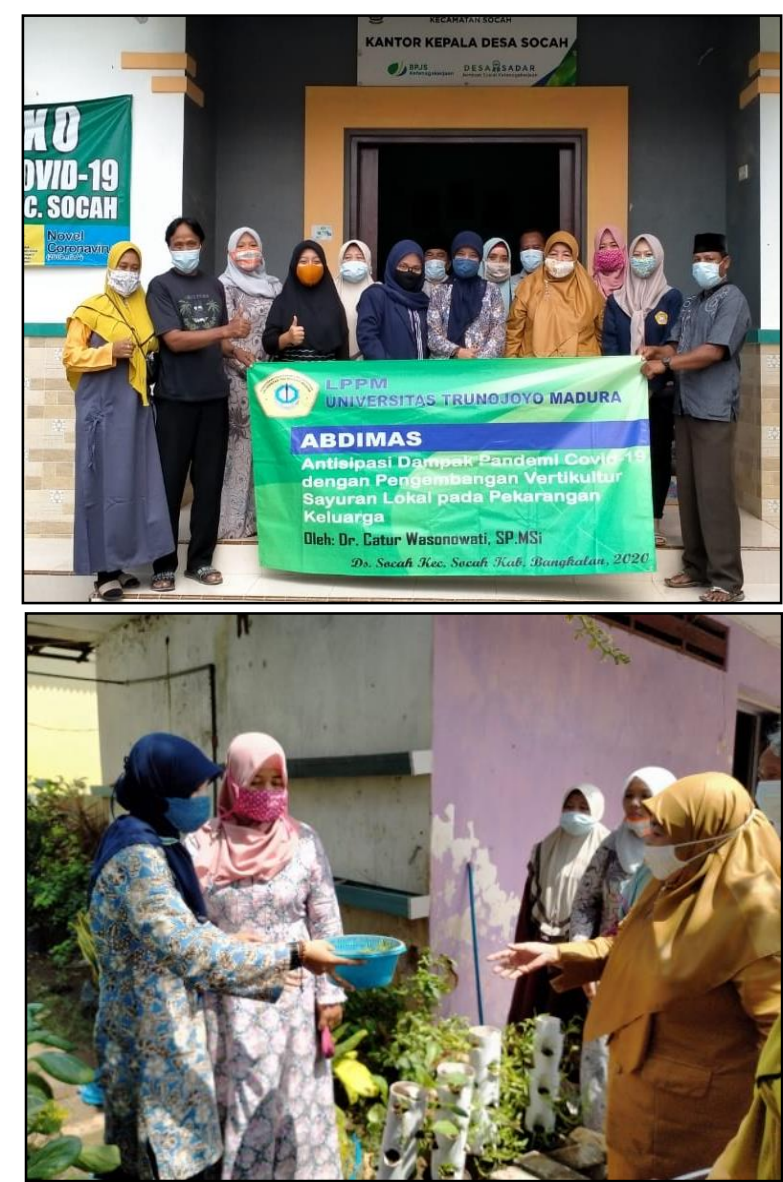

Gambar 1. Sosialisasi dan Pelatihan

Pengembangan Tanaman Sayuran Lokal dengan Metode Vertikultur

Masyarakat yang awalnya tidak tertarik mananam sayuran karena belum tahu manfaat dan cara budidaya dari tanaman sayuran akhirnya bisa dan mampu mengerjakan budidaya tanaman sayuran lokal secara vertikultur untuk mencukupi kebutuhan keluarga. Jenis sayuran yang ditanam adalah sayuran lokal yang disukai keluarganya seperti bayam, sawi, kangkung, selada, kacang panjang dan lain-lain.
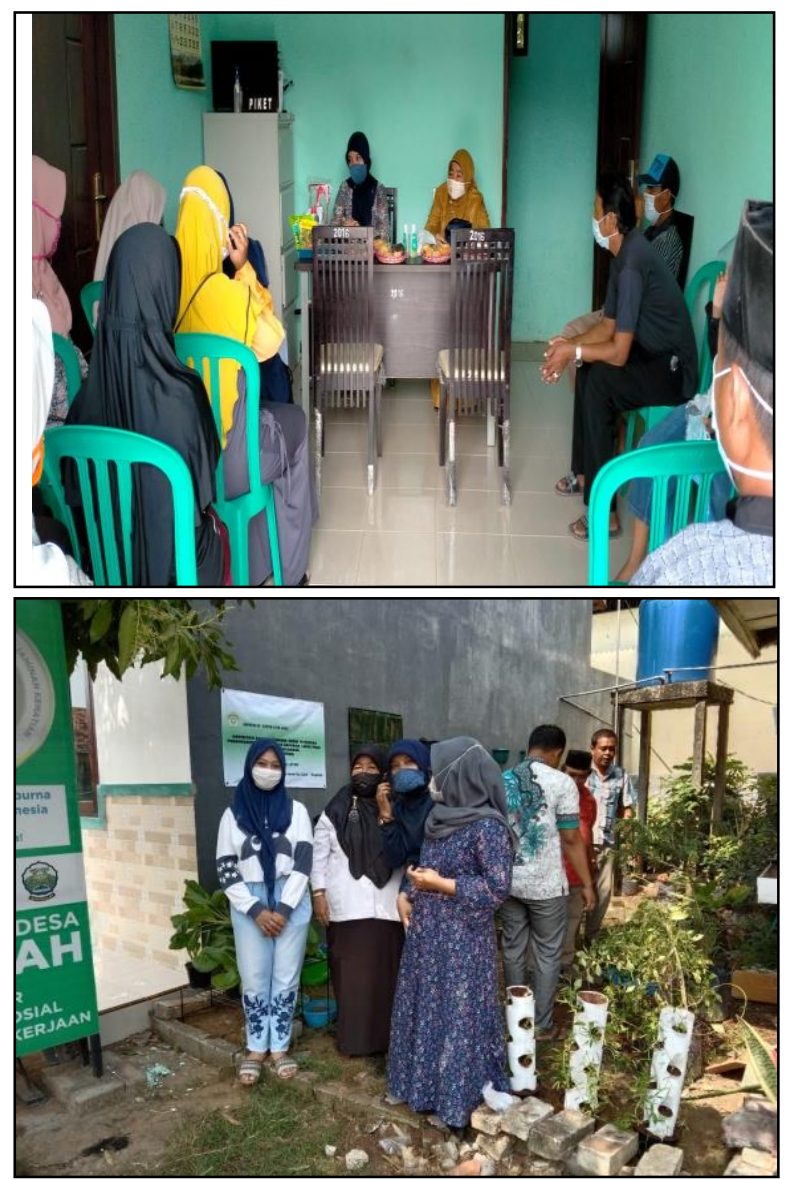

Gambar 2. Pelaksanaan Kegiatan Abdimas

Berdasarkan hasil evaluasi, diperoleh bahwa ibu-ibu rumah tangga dan bapak-bapak perangkat desa sangat bersemangat untuk hadir dalam penyuluhan dan pelatihan budidaya sayuran secara vertikultur. Karena pada saat sosialisasi dan pelatihan pada kondisi pandemi jadi untuk peserta dibatasi jumlahnya tidak lebih dari 15 orang dan menggunakan protokol kesehatan dengan menggunakan masker, mencuci tangan dengan hand-sanitizer dan duduk dengan menggunakan jarak yang renggang. Akan tetapi tingkat kehadiran peserta pada waktu diadakan penyuluhan dan pelatihan budidaya tanaman sayuran lokal secara vertikultur tingkat kehadiran sekitar 90\%. Pengetahuan ibu ibu rumah tangga dan bapak-bapak perangkat desa juga meningkat terkait cara budidaya tanaman sayuran secara vertikultur dan sangat bersemangat untuk menanam sayuran. Ini dapat dilihat pada saat penyuluhan dan pelatihan sangat antusias dan banyak yang bertanya karena keingintahuanya 
tentang bagaimana cara budidaya tanaman secara vertikultur.

Berdasarkan hasil penyuluhan dan peletihan pengabdian kepada masyarakat ini, beberapa ibu peserta sudah mempraktekkan budidaya sayuran secara vertikultur. Alasan ibu ibu yang mau menanam sayuran yaitu supaya tidak membeli sayuran di warung. Produksi tanaman sayuran secara vertikultur jika dikelola dengan baik maka akan menghasilkan produksi yang tinggi dan bagus kualitasnya. Pengelolaan produksi tanaman secara vertikultur meliputi waktu pengolahan lahan atau persiapan media tanam, penyemaian benih, penyiraman benih, perawatan bibit, pemindahan bibit tanaman, penanaman bibit, pemeliharaan tanaman, pengairan, pemupukan, perlindungan dari hama penyakit, panen dan pasca panen.

\section{KESIMPULAN}

Berdasarkan hasil kegiatan abdimas maka dapat disimpulkan ibu-ibu dan bapak perangkat Desa Socah setelah diberi penyuluhan dan pelatihan, diharapkan mampu membudidayakan tanaman sayuran lokal dengan teknik vertikultur dari tanam sampai panen untuk mencukupi kebutuhan pangan dan gizi keluarga.

\section{UCAPAN TERIMA KASIH}

Penulis mengucapkan terima kasih kepada LPPM Universitas Trunojoyo Madura yang telah memberikan dana hibah Pengabdian Kepada Masyarakat melalui Hibah Abdimas Tahun 2020.

\section{DAFTAR PUSTAKA}

Andi D.A.Y, W.A.Rinduwati, Andi N. F dan M. Wiharto. (2018). Teknik vertikultur pada lorong garden. Jurnal Pendidikan Teknologi Pertanian. Vol. 4. 1- 9 pp.
Gumoyo, M. Ningsih, H. Rasyid dan Muhidin. (2016). IBM Budidaya Tanaman Secara Vertikultur. SENASPRO 2016. Seminar Nasional dan Gelar Produk.

Hidayati, N, P. Rosawanti, F. Arfianto dan N. Hanafi. (2018). Pemanfaatan Lahan Sempit Untuk Budidaya Sayuran dengan Sistem Vertikultur. PengabdianMu. Vo 3 (1). 40 - 46 pp.

Nurlaili dan Gribaldi. (2015) Modifikasi Campuran Media Tanam Terhadap Pertumbuhan Tanaman Seledri (Apium Graveolens L.) pada Sistem Vertikultur. Klorofil X - 1:28-31 pp.

Pujorasapto (2006). Budidaya Sayuran dengan vertikultur. Temu Teknis Nasional Tenaga Fungsional Pertanian.

Rukmana, R dan H. Yudirachman, (2016) Budidaya Sayuran Lokal. Penerbit Nuansa Cendekia. 192 h.

Setyaningrum, H.D. (2011) Panen sayur secara rutin di lahan sempit. Penebar Swadaya. Jakarta. $228 \mathrm{~h}$.

Widarto, L. (1997) Vertikultur bercocok tanam secara bertingkat. Penerbit Penebar Swadaya. Jakarta. $130 \mathrm{~h}$

Yosandi DSOAM, M. Baskara, N. Herlian. (2018). Pengaruh Media tanam pada system vertikultur terhadap pertumbuhan dan hasil tanaman bayam merah (Amaranthus tricolor L). Jurnal Produksi Tanaman. Vol 6 (2). 210$216 \mathrm{pp}$. 